\title{
Los proyectos de instauración de tribunales de la Inquisición en la frontera urbana colonial de la región «platina»: Tucumán y Río de la Plata (siglos XVII-XVIII) $)^{*}$
}

\section{The Projected Establishment of the Inquisition on the Colonial Urban Frontier of the 'Silvery' Region: Tucumán and the River Plate (Seventeenth-Eighteenth Centuries)}

JAQUELINE VASSALLO

Universidad Nacional de Córdoba

CONICET

jaquelinevassallo@yahoo.es

\section{RESUMEN}

Este trabajo aborda las propuestas de creación de tribunales de la Inquisición, que generaron autoridades inquisitoriales, reales y eclesiásticas a lo largo de los siglos XVII y XVIII, para contrarrestar la enorme extensión territorial que tenia la jurisdicción del tribunal de Lima y los problemas que derivaban de ello. El estudio se enfoca especialmente en las gobernaciones del Tucumán y el Rio de La Plata, como integrantes de la llamada "región platina»; es decir, un espacio que vinculó núcleos poblacionales de la frontera urbana colonial en los que convivieron portugueses, castellanos, hispano-criollos y lusoamericanos.

*Este trabajo se ha realizado en el marco del proyecto PGC2018-094899-B-C53, Herejía y sociedad en el Mundo Hispánico de la Edad Moderna: Inquisición, imagen y poder (20192021). Asimismo, PAPIIT IG 400619: Religiosidad nativa, idolatría e instituciones eclesiásticas en los mundos ibéricos, época moderna, UNAM, México. 
Palabras clave: Inquisición, Tucumán, Rio de la Plata, Inmigración portuguesa, Iglesia

\section{SUMMARY}

In this work we address proposals for the creation of Inquisition courts by inquisitorial, royal, and ecclesiastical authorities, between the 17th and 18th centuries, due to the immense territorial extension of the Lima court's jurisdiction, and the problems that derived from it. This study specially focuses on the governorates of Tucumán and Rio de la Plata, as part of the so-called «region platina", a space linking population centers of the colonial urban borderland shared by Portuguese, Castilians, Spanish Creoles, and Portuguese Americans.

Keywords: Inquisition, Tucuman, Rio de la Plata, Portuguese immigration, Church

Aposesión española en las Indias, ya que contaba con un extenso territorio que abarcaba desde Panamá hasta el sur de Chile, y del océano Pacífico al Atlántico. ${ }^{1}$ Fue el virrey Francisco de Toledo quien recibió la misión de implementar en el Perú el Tribunal de la Inquisición, la cual no estuvo exenta de dificultades. ${ }^{2}$ La reticencia de los obispos en aceptar una instancia de poder que cercenaba el propio; el rol que jugaron los gobernadores, audiencias y autoridades eclesiales; además de la enorme distancia; la peligrosidad de los caminos, el costo del viaje para trasladar personas y documentos; y la dificultad para encontrar personas idóneas que se desempeńaran como comisarios incidieron en la implementación y la presencia del control inquisitorial en el virreinato del Perú durante más de dos siglos.

Las propuestas de creación de nuevos tribunales de la Inquisición en las ciudades de Buenos Aires y Córdoba fueron abordadas tempra-

${ }^{1}$ Quisbert 2015a, II: 193-214.

2 Quisbert 2015b: 171-191. 
namente por José Toribio Medina en El tribunal del Santo Oficio de la Inquisición en las Provincias del Plata, a fines del siglo XIX. Lo hizo tanto en el capítulo V como en el VIII, y tomó como fuentes los documentos que por entonces se encontraban albergados en el Archivo de Simancas.

Desde entonces, este asunto fue citado y mencionado con mayor o menor profundidad en las obras generales sobre Inquisición de Bartolomé Escandell Bonet y Joaquín Pérez Villanueva- específicamente en los trabajos del primero-, Paulino Castañeda Delgado y Pilar Hernández Aparicio; y en la producción sobre Historia de la Iglesia en Argentina, de Cayetano Bruno, Roberto Di Stéfano y Loris Zanata. ${ }^{3}$

En este trabajo, nos interesa retomar estos aportes que dieron cuenta de las propuestas generadas en torno a las posibilidades de cubrir el control inquisitorial en las gobernaciones del Tucumán y el Río de La Plata a través de la creación de un nuevo tribunal, pero como integrantes de la llamada «región platina». ${ }^{4}$ Es decir, una región que vinculó núcleos poblacionales de la frontera urbana colonial tales como San Pablo, Asunción, Buenos Aires, Santa Fe, Colonia del Sacramento, entre otros; en la que "portugueses, castellanos, hispano-criollos y lusoamericanos compartieron un espacio, interactuaron, se enfrentaron y se complementaron». Y que, en definitiva, como señala Marcela Tejerina, «conformaron una realidad concreta que operó paralelamente al proceso diferenciador que implicaba el reconocimiento de los reinos ibéricos y sus posesiones de ultramar». 5

\section{LA INQUISICIÓN EN LAS «PROVINCIAS DEL PERÚ»}

Desde las últimas décadas del siglo XVI hasta mediados del XVIII, autoridades inquisitoriales, reales y eclesiásticas generaron propuestas

3 Medina 1945; Escandell 1993a: 48-58; 633-659; Castañeda y Hernández 1989-1995; Bruno 1966 y 1968; Di Stefano y Zanata 2000.

${ }^{4}$ Las ciudades que conformaban la región platina eran las siguientes: San Pablo (1660), San Vicente (1532), Santos (1546) y luego en el siglo XVIII se incorporarán Laguna, Porto Alegre, y Río Grande (actual Brasil); Asunción (1537) en el actual Paraguay; Buenos Aires (1580), Santa Fe (1573) en la actual Argentina; Montevideo (1726) y Colonia del Sacramento (1680, en el actual Uruguay) (Tejerina 2018: 12).

5 Tejerina 2018: 10-11. 
de creación de tribunales de la Inquisición en algunas ciudades que conformaban las «Provincias del Perú», con el objetivo de contrarrestar la enorme extensión territorial que tenía la jurisdicción del tribunal de Lima y los problemas que derivaban de ello.

Recordemos que el emplazamiento del tribunal se situaba en la ciudad de Los Reyes, capital del virreinato peruano. Su ámbito jurisdiccional coincidía con los límites del subcontinente meridional americano; es decir, la superficie que ocupan actualmente Panamá, Colombia, Venezuela, Ecuador, Perú, Bolivia, Argentina, Uruguay y Paraguay. Se trataba de una superficie de aproximadamente 3.000.000 de kilómetros cuadrados, lo que Escandell Bonet ha llamado hace ya varias décadas «el gigantismo de los ámbitos jurisdiccionales asignados a cada tribunal». ${ }^{6}$

Los problemas que tuvieron que enfrentar las autoridades inquisitoriales fueron numerosos: una inabarcable jurisdicción territorial, las distancias que separaban a los comisarios del tribunal y de estos con el Consejo de la Inquisición y el inquisidor general, lo que condicionaba la tramitación de las consultas y pulverizaba los plazos procesales. Una consulta del tribunal peruano al Consejo de la Inquisición podía requerir varios años para un circuito completo de ida y vuelta, a lo que debemos sumar los peligros del traslado de la documentación y su supervivencia debido al calor, las ratas y los barcos que se hundían o eran asaltados por piratas. $^{7}$

Además, existían dificultades concretas para el traslado de los reos y reas desde lugares situados a cuatrocientas o seiscientas leguas del Tribunal de Lima - pensemos en alguna persona detenida por un comisario de Córdoba o de Santa Fe, en la actual Argentina_-, los costos económicos que ello conllevaba y el peligro que significaba transitar por rutas inseguras, ya sea por el camino real o cruzando la cordillera de los Andes y luego continuando el viaje por mar (vía Chile, por el Pacífico) hasta el Callao. Sin olvidar la resistencia que opusieron los obispos, que en razón de sus oficios eran inquisidores ordinarios, así como los numerosos

${ }^{6}$ Escandell 1993a: 54; 1993b: 643.

7 Vassallo 2019: 51-68. 
conflictos que se desataron en torno al ejercicio de esa jurisdicción debido a la presencia de la Inquisición. ${ }^{8}$

Ahora bien, la Inquisición había previsto la cobertura de su distrito a través de la designación de comisarios que debían establecerse en puertos de mar y sedes de obispados por la Instrucción de 1569.9 Sin embargo, la implementación no fue inmediata ni lineal. Desde un primer momento, las autoridades civiles y eclesiásticas evidenciaron la necesidad de recortar la enorme jurisdicción territorial del tribunal limeño, y el modo fue la institución de nuevos tribunales. Fue así como Francisco de Toledo escribió a Felipe II para proponerle la fundación de otros tribunales en el Nuevo Reino, Quito y en La Plata, que debían estar conformados por dos oidores y un obispo. ${ }^{10}$ El virrey era consciente del estado de las provincias del Paraguay, Tucumán y Santa Cruz de la Sierra, donde quería asentar uno de ellos, a las que definió en 1578 como «desbaratadas y mal asentadas». ${ }^{11}$

Hacia 1580, el inquisidor Juan Ruiz de Prado, en la visita que hizo al tribunal de Lima y sabiendo que los comisarios estarían separados del mismo por más de seiscientas leguas, propuso al Consejo la delegación de funciones en el obispo más cercano. ${ }^{12}$ Estas propuestas que incluían a los obispos seguramente estaban fundadas en que al momento de la instalación de los tribunales, ellos ejercían funciones inquisitoriales como parte de sus funciones ordinarias, aunque no estuvieron exentos de conflictos, sobre todo con los conquistadores.

Va como ejemplo, el obispo de Asunción, Pedro Fernández de la Torre, quien tenía alguaciles que portaban varas altas y delgadas — una de la Inquisición y otra, la ordinaria- y atravesó serios problemas con el gobernador Felipe de Cáceres, debido a que este se negaba a reconocerle autoridad en materias de Inquisición. Incluso, el gobernador llegó a despojar al alguacil de la vara inquisitorial, lo que le conllevó un proceso en su contra por

\footnotetext{
8 Maqueda 2000: 920.

9 Escandell 1982: 83-84.

10 Tejado 1984: 985.

${ }^{11}$ Bruno 1966-1968, I: 376.

${ }^{12}$ Escandell 1993b: 644.
} 
luteranismo. ${ }^{13}$ Hacia 1586, Alonso Guerra, obispo del Río de la Plata, informaba a Felipe II que el teniente de gobernador Juan de Torres de Navarrete le había negado colaboración en lo tocante a «cosas de la Inquisición», porque en muchos casos debía proceder contra amigos suyos y le inquietaba que enviara a los hombres de su entorno a Lima, bajo el cargo de luteranismo. Al parecer, Fernández de la Torre y Guerra veían indicios de luteranismo en estos hombres que estaban abocados a la conquista, pero no siempre las causas se definieron como ellos imaginaron: Juan de Torres de Navarrete terminó excomulgado por Guerra, pero la Audiencia de La Plata dispuso que el obispo lo absolviese «so pena de temporalidades y extrañamiento de los reinos de España»; ${ }^{14}$ en tanto que Fernández de la Torre murió antes de que Cáceres se embarcara definitivamente a Sevilla para ser juzgado por la Inquisición y de cuyas redes salió airoso. ${ }^{15}$

Las propuestas de incluir a los obispos expresamente en la función inquisitorial no cuajaron, porque suponía una suerte de vuelta a la Inquisición episcopal anterior. ${ }^{16}$ Lo cierto es que esta había sido oportunamente cuestionada por algún funcionario inquisitorial limeño, como lo hizo el fiscal Juan Alcedo al Consejo de la Inquisición en una carta fechada en 1570, en la que seńalaba que el castigo aplicado por los obispos había sido "muy de entre compadres» porque se saldaban mediando composición económica. ${ }^{17}$

Ante la falta de respuesta a las inquietudes planteadas, los inquisidores limeños insistieron en solicitar al Consejo de la Inquisición que las causas originadas en el Río de la Plata, más precisamente en Buenos Aires, fueran tramitadas por la Inquisición de Sevilla debido a que el puerto americano se encontraba más cerca de Espańa que de Lima. ${ }^{18}$ No obstante, el Consejo se limitó a pedirles que «hicieran lo que pudieran» ${ }^{19}$.

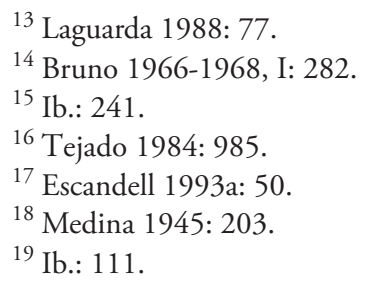


Corría el año 1600, y el inquisidor Antonio Ordóńez informaba al Consejo de la Inquisición sobre las graves consecuencias que derivaban de la desmesurada extensión del distrito del tribunal limeño y replanteaba la jurisdicción total del distrito, proponiendo un recorte hacia el norte y hacia el sur con la creación de los tribunales en Santa Fe y en La Plata respectivamente. El inquisidor fundaba la necesidad de la creación de un tribunal con sede en La Plata, porque entendía que allí se reunían «todos cuantos hombres facinerosos y de malas costumbres hay en estos reinos», ${ }^{20}$ fundamentalmente en la villa del Potosí. A lo que añadía que el "puerto de Buenos Aires, es la escala por donde entran los portugueses ${ }^{21}$ y que los inquisidores tendrían mucho trabajo, aun cuando se nombraran tres. El tribunal que proponía Ordóńez abarcaría los obispados de Charcas, Tucumán, Río de la Plata y la gobernación de Santa Cruz de la Sierra, en cuyo distrito se encontraba la villa imperial de Potosí. ${ }^{22}$

Recordemos que la ciudad de La Plata gozaba de una ubicación ventajosa, ya que se hallaba en la confluencia de las cuencas fluviales amazónica y platense. Desde allí, empezó a organizarse administrativamente el territorio que formaría la Audiencia de Charcas. A partir de 1545, el auge de la plata que se extraía de Potosí estimuló el desarrollo de dicha ciudad, en la que residían mineros españoles enriquecidos y varias órdenes religiosas. Cuando Ordońez propuso instalar un tribunal en La Plata, la ciudad ya era sede episcopal, contaba con una Audiencia, y poco después se convertiría en sede del Arzobispado. ${ }^{23}$ Su obispado era uno de los más grandes de la América hispana. En tanto que la jurisdicción de la Audiencia la colocó en el punto central de contacto entre la zona alta y las tierras bajas orientadas hacia el Río de la Plata, el Tucumán y la zona Amazónica, que por entonces estaba siendo explorada. ${ }^{24}$

Ahora bien, no es casual que tanto la villa de Potosí como Buenos Aires estuvieran en la mira del inquisidor: se trataba de dos ciudades

${ }^{20}$ Tejado 1984: 986.

${ }^{21} \mathrm{Ib}$.

${ }^{22} \mathrm{Ib}$.

${ }^{23}$ Bridikhina y Arce 2015b: 156.

${ }^{24}$ Ib.: $130-133$. 
que estaban unidas por la ruta de intercambio y tráfico del Atlántico sur, que fue impulsada de manera definitiva con la refundación de la ciudad de Buenos Aires en 1580. Esta ruta tenía una serie de ventajas para quienes vivían en el territorio de Charcas y, sobre todo, implicaba menos tiempo de viaje, porque la travesía de Potosí hasta Buenos Aires se realizaba en un primer trayecto en mulas y, luego, con carretas. El viaje duraba aproximadamente tres meses, y tenía una ventaja comparada con la ruta que pasaba por Panamá, que demandaba más tiempo y tenía el grave inconveniente de la condición insalubre del istmo. ${ }^{25}$

La presencia portuguesa a la que aludía Ordoñez coincidía con lo que había apuntado dos años antes el fiscal de la Audiencia de Charcas sobre el puerto de Buenos Aires: «que por atender la navegación por el Brasil, [se] permitía ingresar al Perú negros, mercaderías y portugueses, y daba salida sin licencia ni permiso a la plata y a pasajeros». ${ }^{26} \mathrm{~A}$ propósito de ello, y con la intensión de controlar el flujo migratorio de portugueses que existía entre Buenos Aires y Charcas, la Corona española había emitido reales cédulas fechadas en 1568 y $1581 .{ }^{27}$ No debemos olvidar que la unificación de las Coronas española y portuguesa había creado nuevas oportunidades para la emigración de portugueses, que llegaron a los puertos españoles de América con el fin de ejercer todo tipo de oficios. Muchos arribaron a Brasil y se establecieron en Río de Janeiro, así como en Nueva Granada, las Antillas, Lima y Buenos Aires. En estas dos últimas ciudades, tuvieron una destacada actuación en todos los órdenes de sus actividades sociales —especialmente las mercantiles_durante los dos primeros siglos de la colonización. ${ }^{28}$

Sin embargo, los portugueses —aun entre 1580 y 1640 -, nunca dejaron de ser considerados extranjeros y, como señala Darío Barriera, «sus detractores siempre los tildaron de cristianos nuevos, de judíos o de judaizantes». ${ }^{29}$

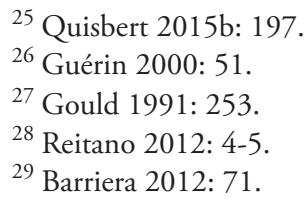


Al momento que Ordoñez proponía la creación de un nuevo tribunal, el obispado de Tucumán se hallaba a cargo del obispo fray Hernando de Trejo y Sanabria. Su antecesor, el dominico de origen lusitano fray Francisco de Victoria, inicialmente había intentado ejercer funciones inquisitoriales, pero el Tribunal de Lima se lo denegó. ${ }^{30}$ Finalmente, en 1585 comenzó a actuar el jesuita Francisco de Angulo como comisario para toda la diócesis del Tucumán, con sede en la ciudad de Santiago del Estero, pero sus actuaciones se concentraron más en perseguir a sacerdotes solicitantes que a supuestos judaizantes. ${ }^{31}$

Al parecer, según señala Eduardo Gould, el control de las «personas que vinieran del Brasil» estaba en manos de las autoridades reales, ya que, a comienzos de 1592, se dispuso que debían dar un fiador que garantizase su presentación ante el gobernador Juan Ramírez de Velazco, que se encontraba en Santiago del Estero, cabeza de la gobernación del Tucumán; de lo contrario, debían pagar una multa de quinientos pesos. Supuestamente, con esta medida se intentaba detener a quienes pretendían subir y radicarse en el Alto Perú, pero no fue del todo eficaz. ${ }^{32} \mathrm{~A}$ principios del siglo XVII, el gobernador interino del Tucumán Francisco de Barrasa y Cárdenas dispuso una orden de expulsión, basada en la real cédula de octubre de 1602, en la que se hacía mención a los «muchos portugueses que han estado por el Río de la Plata y otras partes con los navíos de negros, y cristianos nuevos y gente poco segura». ${ }^{33}$ Lo cierto es que el gobernador la materializó del siguiente modo: «Mandó a todos los dichos portugueses de qualesquier estado, calidad o condición que sean o no fueren pobladores o conquistadores desta provincia o vecinos feudatarios de ella o hijos o nietos suios o que haian entrado en ella con licencia de Su Magestad, salgan de ella». ${ }^{34}$ Les dio dos meses para dirigirse al puerto de Buenos Aires con el objetivo que salieran de «las

\footnotetext{
${ }^{30}$ Bruno 1966-1968, I: 373.

31 Gracia 2006: 75.

32 Gould 1991: 251.

33 Ib.: 256.

${ }^{34}$ Ib.: $256-257$.
} 
Indias», ${ }^{35}$ bajo pena de confiscación total de bienes, destierro perpetuo o servir en las galeras.

Esta real cédula más tarde habilitó al gobernador del Río de la Plata y del Paraguay Hernando Arias de Saavedra a «perseguirlos de manera legal» ${ }^{36}$ : como no eran considerados naturales de los reinos de Castilla, para residir en cualquier ciudad de la monarquía hispánica necesitaban, como cualquier extranjero, una licencia; por lo tanto, en varias ocasiones aplicó esta normativa con la que ordenó expulsar de Buenos Aires a todos los portugueses que no la tuvieran.

Durante la primera década del siglo XVII, Francisco de Trejo comenzó a trabajar como comisario de la Inquisición en Buenos Aires, por ser "puerto de mar» ${ }^{37}$ y en la ciudad de La Plata. En 1608, reclamaba a las autoridades de Lima que llevaran adelante acciones firmes contra los portugueses, porque «Estas provincias están más pobladas de ellos que no de españoles». ${ }^{38} \mathrm{Y}$ pedía instrucciones especiales, ya que no contaba con la colaboración de las autoridades reales; a lo que se le contestó que, en caso que se le dificultara la tarea de las visitas a los barcos que llegaban al puerto, se limitara a informar al Tribunal. ${ }^{39}$ Llegado el año 1610, cuando se creó el tribunal de Cartagena de Indias, el puerto de Buenos Aires se convirtió en una importante opción de ingreso para los portugueses al virreinato del Perú.

Ahora bien, la designación de más comisarios en otras ciudades de las gobernaciones del Tucumán y el Río de la Plata se produjo gracias a diversas gestiones, sobre todo las realizadas por el primer provincial de la Provincia Jesuítica del Paraguay Diego de Torres, quien después de haberlas visitado —incluida la gobernación de Chile_-, llamó la atención de los Inquisidores en 1610: "Juzgo plenamente en el divino acatamiento que la fe de los espańoles dellas, generalmente hablando,

35 Ib.: 256.

36 Barriera 2012: 71.

${ }^{37}$ Castañeda y Hernández 1989-1995, I: 427.

${ }^{38} \mathrm{Ib}$.

${ }^{39} \mathrm{Ib}$. 
tiene muy pocas raíces y tiene muy grande riesgo» ${ }^{40}$ Riesgo que identificaba con el ingreso permanente por los puertos de Buenos Aires, San Pablo y a la ciudad de Asunción de "gente inficionada de judaísmo y de nación portuguesa tan bien se debe velar y cuidar no pasen otras naciones inficionadas con herejías» ${ }^{41}$. Por tanto, solicitaba el nombramiento de comisarios en Córdoba y Asunción, ya que el de Buenos Aires «no podía subir hasta allí». ${ }^{42}$

Lo cierto es que la ruta a la que aludía Torres era la que unía el Río de la Plata con el Brasil, cuya apertura es atribuida al mismísimo obispo Francisco de Victoria, de origen portugués. El llamado «obispo mercader» supo aprovechar los primeros tiempos de la unión de las Coronas para tramitar un permiso que le fue concedido por la Audiencia de Charcas en vistas a hacer comercio con el Brasil, a través de Buenos Aires. Como señala Tejerina, la apertura de esta importante ruta comercial — que llegó a unir a través de Buenos Aires y el Tucumán, la costa brasileña con el Alto Perú-, «debe mucho a su espíritu pionero». ${ }^{43}$ Todo ello supuso un intenso movimiento y establecimiento de personas que provenían de distintas naciones; sobre todo, lusitanos. Esto intranquilizaba a las autoridades por múltiples razones.

La incorporación del puerto de Buenos Aires a dicha ruta favoreció el establecimiento de lusitanos entre fines del siglo XVI y principios del XVII, algunos de los cuales lograron formar parte del naciente grupo de nuevos ricos, lo que les permitió relacionarse con las familias beneméritas por la vía del matrimonio. Y no solo se establecieron en el puerto, sino que también se introdujeron en el mercado rioplatense, radicándose en otras ciudades, como Córdoba y Santa Fe, aunque tuvieron que enfrentar los intentos de ciertas autoridades de limitar su presencia bajo la sospecha de ser judíos o judaizantes, como ya hemos señalado. ${ }^{44}$

${ }^{40}$ Bruno 1966-1968, III: 47; Castañeda y Hernández 1989-1995, I: 52-53; Maeder 2010: 113-133.

${ }^{41} \mathrm{Ib}$.

$42 \mathrm{Ib}$.

43 Tejerina 2018: 48-49. Asimismo, véase Crespi 2001:102.

${ }^{44}$ Tejerina 2018: 51. 


\section{LAS INQUISICIONES EN BUENOS AIRES Y CÓRDOBA}

Mientras el jesuita Torres solicitaba la designación de comisarios, el gobernador del Río de la Plata y el Paraguay, Diego Marín de Negrón, pedía ante la Inquisición de Lima la constitución de un tribunal en Buenos Aires, que se ocupara de juzgar causas vinculadas al Río de la Plata, Tucumán y Chile. ${ }^{45}$ Lo cierto es que, finalmente, se dispuso que en Córdoba y Asunción comenzaran a actuar comisarios. ${ }^{46}$ Asimismo, y en el marco de la unión de las dos Coronas, también se llevaron adelante discusiones sobre la posibilidad de la creación de un tribunal permanente en Brasil, aunque finalmente terminó por definirse con la designación de visitadores. Entre ellos, cabe mencionar la llegada a Bahía en 1618 del visitador Marcos Texeira, que emprendió una vigorosa campaña contra los judaizantes y que, en palabras de José Torre Revello, disparó la migración de muchos de ellos a las regiones del Plata. ${ }^{47}$

Hacia 1619, el capitán Manuel Frías, por entonces procurador general de las Provincias del Río de la Plata, propuso ante la corte de Madrid y en tiempos de Felipe III, la conveniencia de que en el puerto de Buenos Aires existiese un tribunal. ${ }^{48}$ Los fundamentos que esgrimió fueron extensos y los focalizaba estrictamente en la presencia de portugueses, a quienes algunas veces denominaba cristianos nuevos o judíos, pero siempre los vinculaba con la herejía del judaísmo. En primer lugar, Frías señaló que los cristianos nuevos de Portugal «y de otras partes» ${ }^{49}$ ingresaban al virreinato del Perú por Buenos Aires y el Río de la Plata, ya que evitaban hacerlo por Lima y Cartagena, debido a que allí había tribunales inquisitoriales. Buenos Aires y el Río de la Plata les ofrecía la facilidad de ingresar por la costa del Brasil, «que es toda del reino de Portugal y confina con la provincia del Río de la Plata, muy cerca de dicho puerto de Buenos Aires, y ansí dirigiendo su camino al Brasil,

\footnotetext{
45 Bruno 1966-1968, 3: 47.

${ }^{46}$ Castañeda y Hernández 1989-1995, 1: 240.

47 Torre Revello 1929: 17-340.

${ }^{48}$ Medina 1945: 203 y ss.

${ }^{49}$ Bruno 1966-1968, 3: 48.
} 
aguardan allí sus comodidades, conque ocultamente pueden hacer sus entradas y salidas». ${ }^{50}$ Agregaba que la distancia de setecientas leguas que separaba a Lima del Río de la Plata les beneficiaba por las pocas ciudades en las que había "ministros del Santo Oficio de quien puedan ser visitados y reconocidos $»^{51}$. Por lo tanto, las posibilidades de persecución eran menores y podían contar con "grandes comodidades para entrar y salir y contratar encubiertamente y aún descubierta, como lo hacen». ${ }^{52}$ A renglón seguido, Frías señaló que los portugueses eran mayormente «ricos y poderosos, muy inteligentes en todo género de mercaderías y negros, que ocultamente y con otros colores y trazas las meten por dicho puerto». ${ }^{53}$ Y la presencia de ellos en el Río de la Plata, el Tucumán y el Paraguay era entendida como peligrosa por los funcionarios coloniales, ya que temían que convirtieran al judaísmo a los indígenas que habían sido evangelizados. Asimismo, dio cuenta de las redes de protección que tenían para cuidar sus personas y sus bienes y en caso de estar en peligro huían a Brasil e, incluso, eran conducidos a Francia. El procurador estaba convencido de que no bastaba con el trabajo que estaba haciendo el comisario en Buenos Aires, ya que no tenía autonomía suficiente para actuar y la respuesta a una consulta al superior debía recorrer mil quinientas leguas. En cambio, la presencia de un tribunal «atajará la entrada y salida de estos portugueses judaizantes», e incluso, podrá iniciar causas leves sin tener que consultar a Lima». ${ }^{54}$ Asimismo, señalaba que la existencia del tribunal posibilitaría la persecución eficaz, ya que la distancia existente desde el Paraguay y el Río de la Plata a Lima hacía dificultoso y costoso el traslado de los implicados en delitos de fe, razón por la que muchas veces los delitos leves quedaban sin castigo.

Finalmente, proponía que los límites jurisdiccionales del tribunal con sede en Buenos Aires comprendieran las gobernaciones del Río de la Plata, Paraguay y Tucumán «hasta confinar con la provincia de Charcas

${ }^{50} \mathrm{Ib}$.

${ }^{51} \mathrm{Ib}$.

${ }^{52} \mathrm{Ib}$.

${ }^{53}$ Medina 1945: 203 y ss.

${ }^{54} \mathrm{Ib}$. 
[...] con las ciudades de Chile questán de esta parte de la cordillera junto a Tucumán». ${ }^{55}$ Es decir, las ciudades de Mendoza, San Juan de la Frontera y San Luis que conformaban la Gobernación de Cuyo y dependían de la Capitanía General de Chile. ${ }^{56}$ Estas ciudades estaban comunicadas con Buenos Aires por el camino real, lo que facilitaba la circulación de documentos y personas que pudieran ser perseguidas por el tribunal a crearse.

Frías escribía en el momento en que la actividad del puerto de Buenos Aires se hallaba en su clímax, ya que se encontraba ligada a Lisboa y a África, a través de Bahía, debido al dominio que en él tenían los portugueses. Aunque también debemos señalar la presencia de otros barcos europeos que llegaban a través de las «arribadas forzosas». ${ }^{57} \mathrm{El}$ procurador era un hombre cercano al gobernador Hernandarias de Saavedra. Se había desempeńado como teniente de gobernador de Santa Fe y de Buenos Aires, por lo que conocía personalmente buena parte de la «Provincia gigante»; también sabía de las políticas de contención de los bandeirantes portugueses que había emprendido Hernandarias durante su gobierno y el rechazo a los corsarios holandeses que llegaron a Buenos Aires. Ambos habían impulsado el recorte de la jurisdicción de dicha provincia y en el aludido memorial expusieron sus necesidades más urgentes, como la creación de un nuevo obispado para las ciudades del Guairá, la obtención de permiso para exportar productos de dicha provincia a Brasil y a España, la regulación del comercio por Buenos Aires y el combate del contrabando, en el que siempre vinculaban a los portugueses. ${ }^{58}$

Felipe III pasó el memorial a su real Consejo y este lo mandó guardar hasta que estuvieran más informados para tomar una decisión. ${ }^{59}$

$55 \mathrm{Ib}$.

${ }^{56}$ Lobato y Suriano 2010: 56.

${ }^{57}$ Fradkin y Garavaglia 2009: 60; Moutoukias 1999, 3: 77.

${ }^{58}$ En 1616, el rey dispuso la división de dicha provincia, pero no como lo habían solicitado Hernandarias o Negrón, quienes conocían el territorio, sino como lo habían sugerido desde Lima. La nueva provincia del Guairá quedó integrada por Villa Rica del Espíritu Santo, Ciudad Real, Santiago de Xerez y Asunción, capital de la antigua Provincia Gigante. Por su parte, la Provincia del Río de la Plata mantuvo Buenos Aires, Santa Fe, Corrientes, Concepción del Bermejo (Durán 2010: 75-76).

${ }^{59}$ Bruno 1966-1968, 3: 49. 
Finalmente, la división territorial llegó en 1616, cuando por real cédula se creó la Provincia del Paraguay; y, en 1618, Frías fue designado el gobernador de la misma. Pero, en materia inquisitorial, nada lograron: la respuesta obtenida fue que se nombraran comisarios y familiares. Sobre este asunto, Castañeda Delgado y Hernández Aparicio sostienen que el tribunal no se instituyó por motivos económicos. ${ }^{60}$

En abril de 1620, otro informe del tribunal de Lima llegó al Consejo de Indias en el que se señalaba: «El comisario del Santo Oficio de Buenos Aires nos ha escrito en diferentes tiempos, las muchas personas sospechosas de diversas naciones que entran por aquel puerto a estos reinos del Perú, y en particular de la nación portuguesa, cristianos nuevos, pidiendo se le diese orden para el remedio dello». ${ }^{61}$ Fue entonces cuando los inquisidores solicitaron autorización para que el comisario visitara los navíos recién llegados, ya fuere antes o junto con los oficiales reales, con el objetivo de impedir desembarcos de pasajeros indeseables. ${ }^{62}$ Los navíos a los que se referían eran los que zarpaban de Brasil: pequeñas embarcaciones de veinte a cincuenta toneladas, cargadas con algunos esclavos, arrobas de azúcar, aguardiente, un poco de hierro, tejidos y otras manufacturas europeas. ${ }^{63}$ El Consejo dio crédito a este informe por el «muy grande y conocido daño» que podían resentir «las cosas de nuestra santa religión, mayormente en plantas tan nuevas», y los derechos «de las reales rentas expuestas a mermas y concusiones, y el precedente que se creaba para que hiciesen lo propio otras naciones». ${ }^{64}$ Sin embargo, el asunto quedó sin resolver.

Con la llegada al trono de Felipe IV, en 1621, se renovaron las discusiones en torno a la creación de un tribunal en Brasil, como también para fundar uno en el puerto del Río de la Plata. Según señala Ana Pereira, el rey tenía interés de instalar un tribunal en Bahía. ${ }^{65}$ Mientras

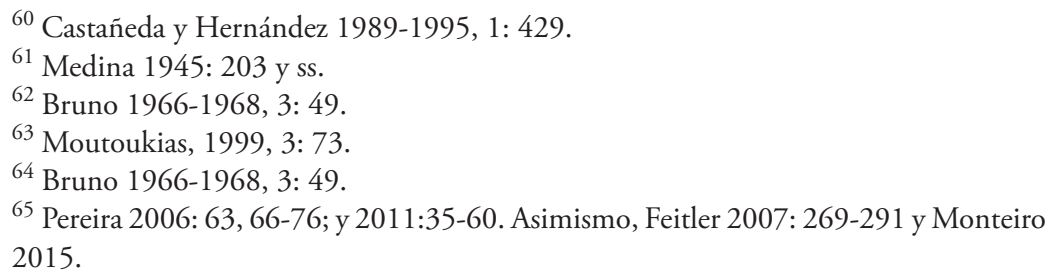


que, en paralelo, en 1623, el Consejo de Indias le desaconsejaba fundar uno en Buenos Aires:

No es cosa practicable [...] porque demás de ser muy poca vecindad los pequeños pueblos que hay en aquella larga y extendida provincia; muy contadas y conocidas las personas que allí habitan, de qué naciones y proceder; y poderse reconocer fácilmente los que entran y salen en ellas, viviendo los que gobiernan con el recato y prevención que conviene, la costa ha de ser muy grande que llegará a diez mil ducados cada año, sin que Vuestra Magestad tenga allí rentas ni aprovechamiento de donde poderlo suplir ${ }^{66}$

Según Cayetano Bruno, la cuestión en el Río de la Plata se cerró porque la Corona no consideró conveniente sostenerlo por motivos económicos, y la solución que propusieron fue que Lima enviase «un comisario de muchas partes» al Río de la Plata, y que el gobierno le diese asistencia. ${ }^{67}$ Mientras tanto, las discusiones por la instauración de un tribunal en Bahía siguieron su curso.

El Tribunal de Lima seguía en guardia. Era consciente que desde 1628 habían entrado a América "gran cantidad de portugueses», muchos de ellos, solteros y sospechosos de herejía, incluso por entonces ya se encontraban tramitando las causas de la llamada "Gran complicidad». ${ }^{68}$ Nuevamente solicitaron la fundación de un tribunal en Buenos Aires, pero la Suprema lo denegó en 1636 y mandó que se destacara un comisario competente. ${ }^{69}$ Ese mismo año, el oidor de la Audiencia de Charcas Sebastián de Alarcón envió un nuevo informe a la corte sobre la presencia de gran cantidad de cristianos nuevos en el Tucumán, quienes «tenían [aquellas tierras] inficcionadas con su mala doctrina, sino también con sus disoluciones y atrevimientos, en gran perjuicio dellas y desacato aun de los mismos templos e imágenes»; por lo que solicitaba se fundase allí un tribunal. ${ }^{70}$

${ }^{66}$ Bruno 1966-1968, 3: 49.

${ }^{67} \mathrm{Ib}$.

${ }^{68}$ Castañeda y Hernández 1989-1995, II: 391 y ss.

${ }^{69}$ Ib.: 387.

${ }^{70}$ Medina 1945: 203 y ss. 
Hacia 1638, el Consejo de Indias requirió la opinión del virrey Luis Jerónimo Fernández de Cabrera y Bovadilla, conde de Chinchón, y de la Audiencia de La Plata. El conde de Chinchón, quien ya estaba en Sevilla, pues había finalizado su mandato, si bien reconoció que el Tribunal de Lima estaba lejos y hacía cuanto podía, entendía que no era conveniente establecer un nuevo tribunal debido, a que las confiscaciones que se obtendrían serían pocas y, por lo tanto, no ayudarían a solventar su funcionamiento. Por su parte, el nuevo virrey marqués de Mancera hacía suyo el parecer de la Audiencia, señalando que ya debería existir desde hace tiempo un tribunal «por los recelos que se han tenido de los muchos portugueses que han entrado por el puerto de Buenos Aires y por el Paraguay». ${ }^{71} \mathrm{La}$ Audiencia de La Plata se manifestó por la creación, ya que consideraba que era necesario "para castigo de los muchos hebreos que tienen inficcionadas aquellas tierras», e incluso señaló a Córdoba como un lugar propicio para establecerlo. ${ }^{72}$

Pero el rey Felipe tenía otros planes: crear un tribunal en Río de Janeiro para detener la entrada de los bandeirantes que capturaban indígenas en el Guairá e impedir que los holandeses accedieran a las riquezas del Alto Perú, con la supuesta complicidad de los cristianos nuevos que vivían en Brasil. ${ }^{73} \mathrm{Al}$ parecer, su decisión tomaba como base la información del jesuita Antonio Ruíz de Montoya expuesta en un memorial que le presentó en Madrid mientras se desempeñaba como procurador de las provincias del Paraguay y del Río de la Plata. Ruíz de Montoya era un afamado jesuita que había vivido muchos años en las reducciones del Paraguay. Siendo superior de la misión, dispuso la evacuación de las últimas reducciones que no habían sido atacadas por los bandeirantes en el Guayrá; en 1631, los indios emigrados arribaron con muchas pérdidas a las tierras de Misiones (hoy Argentina), donde fundaron las poblaciones de San Ignacio y Loreto. ${ }^{74}$ Sin embargo, el rey disentía con el jesuita en la sede que este le proponía: la ciudad de Córdoba, cabecera

\footnotetext{
${ }^{71}$ Medina 1945: 203 y ss; Castañeda y Hernández 1989-1995, II: 423-424.

72 Medina 1945: 203 y ss.

${ }^{73}$ Véase el artículo de Pereira en este dosier.

${ }^{74}$ Maeder 1999: 441; Avellaneda 2016: 52-53.
} 
de la provincia jesuítica del Paraguay, que se hallaba en el «centro de la jurisdicción", "frontera de portugueses y en la que habitaban muchos que llegaban por mar y tierra». ${ }^{75}$ Recordemos que hacia fines del siglo XVI y aún durante los primeros decenios del siglo XVII, Córdoba se había convertido en una verdadera plaza mercantil a la que habían llegado comerciantes portugueses en donde se asentaron e, incluso, ocuparon cargos en el cabildo. ${ }^{76}$

Felipe IV organizó una Junta para que opinase sobre la conveniencia de crear un tribunal, sobre todo teniendo en cuenta los problemas que atravesaba la Real Hacienda. Según Cayetano Bruno, Ruíz de Montoya continuó completando su propuesta inicial en vista a facilitarle la toma de la decisión: reducir el número de curas de la iglesia de Potosí, aprovechar las rentas de beneficios vacantes y adjudicar al tribunal una prebenda de las iglesias catedrales de Chile y Tucumán. ${ }^{77}$ Finalmente, la "Restauración» de Portugal deshizo los planes del rey para instituir un tribunal en Río de Janeiro, ${ }^{78}$ pero tampoco se decidió por la creación de un tribunal en Córdoba por los gastos de mantenimiento que suponía; y menos aún en Buenos Aires, por temor a que la ciudad fuera invadida por "herejes», el tribunal fuese «ofendido» y los presos liberados. ${ }^{79}$

Así fue como la Inquisición siguió presente bajo la estructura de comisarías tanto en Buenos Aires como en Córdoba. Y, al parecer, está última actuó al respecto, ya que entre 1636 y 1677, fueron apresados once portugueses, acusados de judaizar y practicar y «otras herejías». ${ }^{80} \mathrm{~A}$ principios de la década del 60, el tribunal limeño retomó sus solicitudes ante el Inquisidor General, alentado por la creación de una Audiencia pretorial en Buenos Aires (1661) y cuyo distrito quisieron hacer coincidir con el del tribunal inquisitorial: las gobernaciones del Río de la Plata, Paraguay y el Tucumán. La Audiencia había sido creada con el objetivo

75 Bruno 1966-1968, 3: 50.

76 Gould 1991: 252.

77 Bruno 1966-1968, 3: 50.

${ }^{78}$ Véase el artículo de Pereira en este dosier.

${ }^{79}$ Medina 1945: 203 y ss.

${ }^{80}$ Sartori 2017: 285. 
de proteger al Río de la Plata de probables ataques enemigos, impedir el contrabando que afectaba a la Real Hacienda y defender los intereses de los comerciantes de Sevilla, Cádiz y Lima perjudicados por el contrabando. ${ }^{81} \mathrm{Al}$ parecer, se entendía que estas dos instituciones reforzarían la custodia de los intereses de la Corona. No debemos olvidar que, desde 1640 y en el marco de la guerra de España con las Provincias Unidas holandesas, el actor principal de ese tráfico fue Holanda, cuyas naves entraban en el Río de la Plata en concepto de «arribadas» más o menos clandestinas. ${ }^{82}$ Los inquisidores limeños señalaban que la comunicación por mar entre la península y Buenos Aires no era "dilatada ni dificultosa», con lo cual proponían que allí podía funcionar un tribunal integrado por dos inquisidores, un fiscal y otros ministros; o en su defecto, un inquisidor, un fiscal «y demás ministros forzosos». ${ }^{83}$ Demás está decir que esta iniciativa no terminó de cuajar.

Lo cierto que es aún a mediados del siglo XVIII, todavía existieron propuestas que provenían de distintas iniciativas, fundamentalmente porque por ese entonces se percibía el aumento del poder de Buenos Aires como consecuencia directa de sus campañas contra los portugueses. ${ }^{84}$ Entre ellas, podemos mencionar la del jesuita Juan de Escandón, quien, en ocasión de haber sido nombrado calificador del Tribunal de Lima, se dirigió desde Buenos Aires al Inquisidor General para manifestar la necesidad de crear un tribunal en esa ciudad debido a la presencia de judaizantes. Entre sus reclamos, podemos rescatar:

tan fuera de tiempo que no sirve, lo cierto y sin duda es, que los veinte años que aquí yo estoy en estas provincias, nunca he visto ni oído que de ninguna de ellas se hayan preso ninguno por la Inquisición, sino uno solo en Buenos Aires, y ese no llegó a la Inquisición, sino que se escapó a pocos días de camino y no se ha vuelto a coger. ${ }^{85}$

\footnotetext{
${ }^{81}$ Levaggi 1987: 20.

${ }^{82}$ Fradkin y Garavaglia 2009: 60.

${ }^{83}$ Medina 1945: 203 y ss.

${ }^{84}$ Lobato y Suriano 2010: 76.

${ }^{85}$ Di Stefano y Zanata. 2000: 81.
} 
En 1765, el arzobispo de la Plata, Pedro Miguel, dirigió a Carlos III un Memorial en el que planteaba la necesidad de establecer el Tribunal del Santo Oficio en Buenos Aires:

Siendo casi inmensa la distancia que intermedia del Paraguay a la ciudad de Lima, tengo experiencia en los quince años de posesión en Córdoba, que ocurriesen muchos casos pertenecientes a la Inquisición, cuyo recurso, por tan difícil, motivan quedar impunidos los delitos, por lo que soy de parecer que se sirva V.M. exigir un Tribunal de la Inquisición en la ciudad de Buenos Aires, para que, siendo inmediato el recurso del Paraguay y Córdoba, sirva al mismo tiempo de inquirir la mala semilla que contra la fe católica pueden sembrarlos que de diferentes naciones comercian en aquel puerto, impidiendo el que no contagien lo sano de estas partes. ${ }^{86}$

La respuesta, fechada en diciembre de 1766, negó la posibilidad de la creación, ya que en Madrid les constaba "por notoriedad que allí son muy raros los reos de fe, por el sumo cuidado que siempre se ha puesto en que no pasen a los reinos de Indias descendientes de herejes». ${ }^{87}$

Al parecer, Carlos III confiaba en el trabajo de control que ejercían el Consejo de Indias y la Casa de Contratación para que no embarcaran hacia estas tierras aquellos que lo tenían prohibido. Sin embargo, el arribo de lusitanos que pertenecían a distintos estratos sociales - y a quienes se los seguía vinculado con la herejía - se mantuvo constante. Para ellos, señala Emir Reitano, «Buenos Aires continuaba siendo una ciudad más, dentro del espacio atlántico, en la que las circunstancias de crecimiento permitían una vida mejor, dejando en segundo plano su pertenencia a la Corona española». ${ }^{88}$ El 18 de mayo de 1784, el Tribunal de Lima envió una carta al Consejo que acompañada de relaciones de causas, y en la que continuaba señalando que «se siguen introduciendo hebreos entre los muchos que tiene el comercio libre (concluida la guerra) se introducen por la vía de Buenos Aires y los que se esperan». ${ }^{89}$

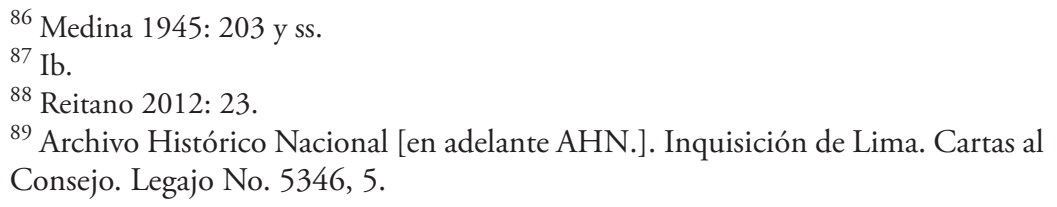


Los problemas que causaba la distancia entre los inquisidores de Lima y los comisarios estuvieron lejos de subsanarse, aun cuando en el Tucumán y el Río de la Plata se nombraron algunos más en ciudades donde había circulación económica, pero por sobre todo presencia portuguesa. Así lo vemos en una carta escrita en 1804 por los inquisidores limeńos al Consejo, en la que comunicaban la demora que tendrían en tramitar cierta diligencia ante los comisarios de sus distritos, ya que «algunos residen en tal distancia que la contestación más pronta exige de quatro meses de tiempo». ${ }^{90}$

\section{A MANERA DE CONCLUSIÓN}

La idea de estudiar la implementación de la Inquisición, o de las Inquisiciones en plural, tanto en el Tucumán como en el Río de la Plata como parte de la región platina, intenta trascender el punto de vista de las «historias nacionales» de las que no siempre los estudios inquisitoriales pudieron sustraerse. Asimismo, nos permite ampliar el panorama de las discusiones que fueron propiciando las autoridades coloniales ante los monarcas e inquisidores, incluyendo las decisiones que tomaron los reyes durante la Unión de las dos Coronas para el Brasil; y así, entender ciertas negativas de crear un tribunal en el Río de la Plata.

Evidentemente, la "amenaza portuguesa» —léase cristianos nuevos, judaizantes_-, fue reiteradamente planteada con el fin de obtener de la Corona la respuesta esperada, aunque no siempre persiguió motivos religiosos, sino también económicos - y en esto no hay que ser ingenuos- Sin embargo, los monarcas una y otra vez dispusieron que el control inquisitorial de las regiones del Tucumán y el Río de la Plata, fuera cubierto por comisarios que se nombraron durante los siglos XVII y XVIII en otras ciudades, como Corrientes, Santa Fe, Salta, La Rioja y Catamarca. Y a la par, implementaron medidas concretas en relación a los portugueses, que obviamente variaron de acuerdo a las relaciones políticas que tuvieron con el reino de Portugal en distintos momentos históricos a través de las autoridades coloniales. Fue entonces cuando,

${ }^{90}$ AHN. Inquisición de Lima. Cartas al Consejo. Legajo No. 2218, 1. 
en algunas ocasiones, se los trató como extranjeros o delincuentes, pero no como herejes. Lo cierto es que los portugueses jugaron un rol social y económico en el orden colonial importante y la Corona, así como algunas autoridades locales, lo sabían. Por lo tanto, las llamas de la Inquisición podían esperar.

\section{BIBLIOGRAFÍA}

Avellaneda, Mercedes. 2016. «Guerra y milicias jesuíticas en la expansión territorial de la frontera contra el imperio lusitano, siglos XVII y XVIII». En Salinas, María Laura y Lía Quarleri (coords.). Espacios misionales en diálogo con la globalidad iberoamericana. Resistencia: Con Texto Libros; Universidad Nacional del Nordeste; Facultad de Humanidades: Conicet; Instituto de Investigaciones Geohistóricas, 49-74.

Barriera, Darío. 2012. "Tras las huellas de un territorio». Historia de la Provincia de Buenos Aires. De la Conquista a la crisis de 1820. Buenos Aires: EDHASA y UNIPE: Editorial Universitaria, vol. 2, 53-84.

Bridikhina, Eugenia y Silvia Arce. 2015a. «El establecimiento del sistema administrativo». En Bolivia, Su Historia. Tomo 2. La experiencia colonial en Charcas, siglos XVI-XVII. La Paz: Coordinadora de Historia, 131-135.

Bridikhina, Eugenia y Silvia Arce. 2015b. «En intento de dominio sobre el territorio». Bolivia, Su Historia. La experiencia colonial en Charcas, siglos XVI-XVII. La Paz: Coordinadora de Historia, vol. 2, 151-166.

Bruno, Cayetano.1966-1968. Historia de la Iglesia en la Argentina. Buenos Aires: Editorial Don Bosco, 3 vols.

Castañeda Delgado, Paulino y Pilar Hernández Aparicio. 1989-1995. La Inquisición de Lima. Madrid: Demos, 2 vols.

Crespi, Liliana. 2001. "Comercio de esclavos en el Río de La Plata durante el siglo XVII». En Cáceres, Rina (comp.). Rutas de la Esclavitud en África y América Latina. San José de Costa Rica: Editorial de la Universidad de Costa Rica, 101-114.

Di Stefano, Roberto y Loris Zanata. 2000. Historia de la Iglesia en Argentina. Desde la Conquista hasta fines del siglo XX. Buenos Aires: Grijalbo Mondadori.

Durán Estragó, Margarita. 2010. «Conquista y colonización». En Telesca, Ignacio (coord.). Historia del Paraguay. Asunción: Taurus, 63-86.

Escandell Bonet, Bartolomé. 1982. «La Inquisición Española en Indias y las condiciones americanas de su funcionamiento». En La Inquisición. Madrid: Ministerio de Cultura, 81-91.

Escandell Bonet, Bartolomé. 1993a. «Estructura geográfica del dispositivo inquisitorial americano». En Escandell Bonet, Bartolomé y Joaquín Pérez Villanueva (coords.). Historia de la Inquisición en España y América. Las estructuras del Santo 
Oficio. vol. II, Madrid: Biblioteca de Autores Cristianos y Centro de Estudios Inquisitoriales, 48-62.

Escandell Bonet, Bartolomé. 1993b. «La peculiar estructura administrativa y funcional de la Inquisición española en Indias» En Escandell Bonet, Bartolomé y Joaquín Pérez Villanueva (coords.). Historia de la Inquisición en España y América. Las estructuras del Santo Oficio. Vol. II. Madrid: Biblioteca de Autores Cristianos y Centro de Estudios Inquisitoriales, 633-659.

Feitler, Bruno. 2007. "Usos políticos del Santo Oficio portugués en el Atlántico (Brasil y África Occidental)». Hispania Sacra. Volumen 9, número 11, 269-291. https://doi.org/10.3989/hs.2007.v59.i119.30

Fradkin, Raúl y Juan Carlos Garavaglia. 2009. La Argentina Colonial. El Río de la Plata entre los siglos XV y XIX. Buenos Aires: Siglo XXI Editores.

Gould, Eduardo. 1991. «La condición de extranjero en América: los portugueses en Córdoba del Tucumán entre 1573 y 1640». Revista de Historia del Derecho. Número 19, 246-279.

Gracia, Joaquín. 2006. Los jesuitas en Córdoba. Desde la Colonia hasta la Segunda Guerra mundial. 1585-1626. Córdoba: Editorial de la Universidad Católica de Córdoba, tomo 1.

Guérin, Miguel Alberto. 2000. «La organización inicial del espacio rioplatense». En Tandeter, Enrique (coord.,). Nueva Historia Argentina. Sociedad colonial. Buenos Aires: Sudamericana, tomo II, 17-53.

Laguarda Trías, Rolando. 1988. Pilotos portugueses en el Rio de la Plata durante el siglo XVI. Lisboa: Instituto de Investigação Científica Tropical.

Levaggi, Abelardo. 1987. Manual de Historia del Derecho Argentino. Buenos Aires: Depalma, tomo II.

Lobato, Mirta y Juan Suriano. 2010. Nueva Historia Argentina. Atlas Histórico. Buenos Aires: Sudamericana.

Maeder, Ernesto. 1999. «La Iglesia misional y la evangelización del mundo indígena». Nueva Historia de la Nación Argentina. Periodo español (1600-1810). Buenos Aires: Planeta, tomo 2, 433-468.

Maeder, Ernesto. 2010. «Las misiones jesuíticas». En Telesca, Ignacio (coord.). Historia del Paraguay. Asunción: Taurus, 113-133.

Maqueda Abreu. 2000. Consuelo. Estado, Iglesia e Inquisición en Indias. Un permanente conflicto. Madrid: Centro de estudios Políticos y Constitucionales.

Medina, José Toribio. 1945. La Inquisición en el Río de La Plata. El Tribunal del Santo Oficio de la Inquisición en las Provincias del Plata. Buenos Aires: Editorial Huarpes.

Monteiro, Lucas Maximiliano. 2015. A inquisição não está aqui? A presença do Tribunal do Santo Oficio no extremo sul da América Portuguesa (1680-1821). São Paulo: Paco Editorial.

Moutoukias, Zacarías. 1999. «Comercio y producción». Nueva Historia de la Nación Argentina. Período español (1600-1810). Buenos Aires: Planeta, tomo III, 51-103. 
Pereira, Ana Margarida Santos. 2006. A Inquisição no Brasil. Aspectos da sua actuação nas Capitanias do Sul (de meados do séc. XVI ao princípio do séc. XVIII). Coimbra: Faculdade de Letras - Universidade de Coimbra.

Pereira, Ana Margarida Santos. 2011. «Terceira Visitação do santo ofício às partes do Brasil. Capitanias do sul, 1627-1628». História e Sociedade, Vitória da Conquista. Volumen 11, número. 1, 35-60.

Quisbert Condori, Pablo. 2015a. «Francisco de Toledo y el establecimiento del orden colonial (1570-1580)». En Bridikhina, Eugenia (coord.). Bolivia, su Historia. La experiencia colonial en Charcas, siglos XVI-XVII. La Paz: Coordinadora de Historia, tomo II, 171-191.

Quisbert Condori, Pablo. 2015b. «El período de la consolidación (1582-1600)». En Bridikhina, Eugenia (coord.). Bolivia, su Historia. La experiencia colonial en Charcas, siglos XVI-XVII. La Paz: Coordinadora de Historia, tomo II, 193-214.

Reitano, Emir. 2012. Los portugueses del Buenos Aires tardocolonial: Inmigración, sociedad, familia, vida cotidiana y religión. Tesis de Doctorado en Historia. La Plata: Universidad Nacional de La Plata.

Sartori, Federico. 2017. Inquisición y sociedad en Córdoba el Tucumán (1573-1699). Tesis de Doctorado en Historia. Córdoba: Universidad Nacional de Córdoba.

Tejado Fernández, Manuel. 1984. «La ampliación del dispositivo: Fundación del Tribunal de Cartagena de Indias» En Escandell Bonet, Bartolomé y Joaquín Pérez Villanueva (coords.). Historia de la Inquisición en España y América. El conocimiento cientifico y el proceso histórico de la institución (1478-1834). Madrid: Biblioteca de Autores Cristianos y Centro de Estudios Inquisitoriales, vol. 1, 984-995.

Tejerina, Marcela. 2018. Frontera urbana, frontera colonial. Historias (s) de la región platina durante el dominio de las coronas ibéricas (siglos XVI al XIX). Rosario: Prohistoria.

Torre Revello, José. 1929. «Nuevos datos para el estudio de la Inquisición en el Río de la Plata». Humanidades. Número 20, 317-340.

Vassallo, Jaqueline. 2019. "Consideraciones sobre el problema de las fuentes judiciales para el estudio de la Inquisición en América. El caso del tribunal de Lima». Temas Americanistas. Número 42, 51-68.

Fecha de recepción: 31/III/2020

Fecha de aceptación: 22/VI/2020 